\title{
Primera Convención Nacional de Obstetricia y Ginecologia
}

\author{
Organizada por la
}

-Sociodad Colombiana de Obstetricia y Ginocología.

19-Lugar y techa de la Convonción: La primera Convención Nacio. nal de Obstetricia y Ginecologia tendró lugar en Bogotá, durante los días 9. 10, 11 y 12 de septiembre de 1953. Tanto las reuniones científicas como las actos sociales se efectuarión en uno de los salones del Hotel Tequendama.

2 -Personal: Integrarón la primera Convención Nacional de Obstetricia $y$ Ginecología, todos los médicos, nacionales y extramjeros residentes en Co. lombla, que sé dediqueis a una de las dos especialidades, Obstetricia o $\mathrm{Gi}$ necología y que deseen tomar parte en ella, inscribléndose dentro de 108 plazos señalados ya sea personalmente 0 por correspondencia, en la Secretaría General de la Sociedat Colombiana de Obstetricia y Gineco. logía: Bogotá, Carrera 12 № 20-69 Of. 302.

3-Temas Clontíficos: Los tomas científicos que se quieram presentar. a la Convención para las dos espe claildades son Hbres. Sin embargo, la Sociedad Colombiana de Obstetricla y Ginecología se permilte recomendar a los especialistas los siguientes temas: Obstatudetar a) Toxdconis Gravidica: b) Factor \&Rh" y Extroblactoals Fotal; CI. nocoloria: a) Enterlidadi b) Endome. wods.
49-Plasos para la insecipelón: (9) El plazo para inscribir $y$ enviar los trabajos científlcos, estadísticas, proyec ciones, etc., comprende hasta el 29 de agosto de 1953. 29) El plazo para la inscripción de los médicos Obstetras y Glnecólogos residentes fuera de Bogotá, comprende hasta la misma fecha. Para reservaciones dirigirse directamente al Hotel Tequendama, o al que conside. ren de su agrado. La Avianca hace descuentos especiales a quienes vengan a la Convención.

50--Valor de la Inscripalon: El valor de la inscripción para tomar parte en la Convenctón es de treinta pesos (\$ 30.00$)$ moneda corriente, que se consignarán en la Secretaría de la Socledad al inscribir y enviar los traba. jos, o en la Tesorería de la misma. antes del 29 de agoste de 1953. Esta consignación da derecho a las publicaciones que de los trabajos científcos presentados a la Convención, hará la Sociedad Colombiana de Obste tricia y Ginecologia, y a ia asistencia tanto a los actos científicos como a los sociales.

69-En esta Convención, es Ajartm: \lugar, la focha y los tomas pasa la escrunda Convenetón Necloned do Obototida 7 Ctoveoloote. 